\title{
Preparation, Validation and User-testing of Patient Information Leaflets on Diabetes and Hypertension
}

\author{
SANTOSHA VOORADI, LEELAVATHI D. ACHARYA*, SHUBHA SESHADRI ${ }^{1}$, G. THUNGA AND K. VIJAYANARAYANA \\ Department of Pharmacy Practice, Manipal College of Pharmaceutical Sciences, ${ }^{1}$ Department of General Medicine, Kasturba \\ Medical College, Manipal Academy of Higher Education, Manipal-576 104, India
}

Vooradi, et al.: Preparation, Validation, and User-testing of Patient Information Leaflets

\begin{abstract}
A patient information leaflet is an educational material for educating patients regarding a disease, medications and lifestyle modifications for better care. The present study aimed at preparing, validating and user-testing of diabetes and hypertension information leaflets in different languages among patients. The patient information leaflets on diabetes and hypertension were prepared by referring to the primary, secondary and tertiary resources. The content of the leaflet was validated by an expert committee. The readability of leaflets has been assessed by Flesch Reading Ease and Flesch-Kincaid Grade Level scores using MS Office 2007. The patient information leaflets were translated into Kannada and Malayalam languages with the help of language experts. During the user-testing, baseline knowledge was assessed before providing the patient information leaflet followed by provision of leaflets to the patients. After allowing the patients to read the leaflet for a period of $20 \mathrm{~min}$, patients have again been administered with a set of questions to assess their knowledge. The Flesch Reading Ease and Flesch-Kincaid Grade Level readability scores achieved for diabetes leaflets are 70.4 and Flesch-Kincaid Grade Level score achieved is 6.3 and for hypertension leaflets, the Flesch Reading Ease score is 68.3 and Flesch-Kincaid Grade Level score achieved is 6.9. User testing of the patient information leaflets on diabetes and hypertension in different languages have been carried out on 40 each diabetic and hypertensive patients using knowledge based questionnaire. Knowledge assessment after providing patient information leaflet, the mean scores have significantly risen from 44.80 to 87.99 and 63.19 to 90.13 with $p<0.0001$, respectively in diabetes and hypertensive patients. It showed that patient education added with a well-designed patient information leaflet has a greater impact on knowledge of the patients towards their disease management, so that the medication adherence is improved.
\end{abstract}

Key words: Patient information leaflets, patient education, diabetes, hypertension, lifestyle modifications

Patient information leaflet (PIL) is an educational material for conveying patient education regarding disease, medications and lifestyle modifications for better patient outcomes. A PIL is a legal document included in every medicine package to present written information about the medication use. Patient education is one of the major management strategies for curing or preventing the progression of many chronic diseases. PILs are the best-utilized tools for the patients with chronic disorders such as diabetes, pulmonary disease, and rheumatoid arthritis. Lack of information has been identified as a major factor for the patients' improper medication. Hence patients must know their therapy properly to adhere to the medication. Providing patients with PILs was found to be effective in improving patients' knowledge, compliance and the awareness of their potential side effects ${ }^{[1]}$. hypertension (HTN), asthma, chronic obstructive

Written patient information is frequently used for the benefit of patients to complement communication with the doctors. It can also help reconcile the communication gap between the patient and the physicians and emphasize the warnings and instructions. Written information can draw the attention of the patients leading to medication adherence and change in their lifestyle. Manufacturers are providing PILs along with their products, which provides information on their medication regarding its administration, precautions and potential side effects ${ }^{[2]}$. As per the Article 11 of Directive 2001/83/European Commission (EC), the

This is an open access article distributed under the terms of the Creative Commons Attribution-NonCommercial-ShareAlike 3.0 License, which allows others to remix, tweak, and build upon the work non-commercially, as long as the author is credited and the new creations are licensed under the identical terms

Accepted 28 November 2017

Revised 17 April 2017

Received 11 October 2016

*Address for correspondence E-mail: leela.da@manipal.edu

January-February 2018

Indian Journal of Pharmaceutical Sciences 
content of PILs should be unbiased, evidence-based and presented in a clear, understandable and well readable way to suitable for laypersons ${ }^{[3]}$. The EC issued a Guideline on the readability of the label and package leaflet of medicinal products for human use, which provided guidance on how to prepare well-readable and understandable package leaflets. As of November 2005, the EC guideline led to the introduction of readability user tests to demonstrate the readability and usefulness of the package leaflet to patients ${ }^{[4]}$.

Dowse et al. carried out the study to determine the influence of medicine labels incorporating pictograms on the understanding of instructions and on their adherence. The presence of pictograms was found to contribute positively both to the understanding of instructions and adherence ${ }^{[5]}$. Diabetes is a life-long disease, difficult to treat, often leads to a variety of acute and chronic complications, seriously affecting the patient's quality of life ${ }^{[6]}$. Kheir et al. evaluated the knowledge, attitude, practice (KAP) and psychological status of adult Qatari patients with type 2 diabetes mellitus to study the role of these factors in the ability of the patients to manage their diabetes and to achieve desirable health outcomes ${ }^{[7]}$. According to Norris et al., 50-80 \% of diabetic patients have little knowledge about their disease and few skills to put to practice ${ }^{[8]}$. McMurray et al. clearly showed that diabetes education and care management can significantly improve the patient outcomes, glycemic control and quality of life in diabetic patients ${ }^{[9]}$. HTN is a serious and common condition, the prevalence of which is set to increase in the aging population, sedentary lifestyles and obesity ${ }^{[10]}$. Studies have shown that dietary habit is an important lifestyle factor impacting on the risk of developing $\mathrm{HTN}^{[10]}$. A study conducted by Arul et al. revealed the knowledge on HTN based on the questionnaire scores and the study confirmed that education with PIL significantly improved their knowledge regarding HTN. It may be concluded that the disease-specific knowledge through PILs is necessary to strengthen patients' self-confidence in the management of the disease and to improve self-management ${ }^{[11]}$. The Dietary Approaches to Stop Hypertension (DASH) and the DASH-sodium trials are proved that dietary patterns are rich in vegetables, fruits, and low-fat dairy products and less in sodium, total fat, saturated fat, and dietary cholesterol lowers blood pressure effectively in prehypertensive and hypertensive adults ${ }^{[12]}$.

The glycemic control and blood pressure control is dependent on various factors such as the patient's adherence to drugs, lifestyle changes and regular monitoring of blood glucose and blood pressure. This is highly influenced by effective patient education and counselling ${ }^{[2]}$. Providing PILs containing all the information related to disease and its management along with lifestyle changes required by the patient will definitely help to maintain the blood glucose level and blood pressure, thereby preventing the complications by adhering to medication and with proper lifestyle modifications. So, the present study is aiming at preparing well designed PIL for diabetes and HTN. It can be further used by the clinical pharmacist during patient counseling either to inpatients or outpatients.

\section{MATERIALS AND METHODS}

The present study has been conducted for a period of eight months between August 2014 and March 2015 at a tertiary health care hospital in south Karnataka. Approval of the Institutional Ethics Committee (Ref. no. IEC 503/2014) has been obtained prior to the initiation of the study.

\section{Preparation, validation, and translation of PILs on diabetes and HTN:}

PILs were prepared for diabetes and HTN diseases and common drugs used for the treatment by referring primary, secondary and tertiary resources. Tertiary resources included Pharmacotherapy: A Pathophysiologic Approach ${ }^{[13,14]}$, Textbook of Therapeutics: Drug and Disease Management ${ }^{[15,16]}$, Harrison's Principles of Internal Medicine ${ }^{[17,18]}$. The secondary resources were various databases such

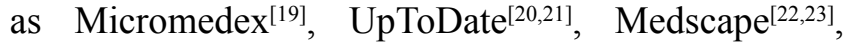
Medline ${ }^{[24,25]}$ and WebMD ${ }^{[26,27]}$. The primary resources included various articles related to patient education and information leaflets on diabetes ${ }^{[28,29]}$ and $\mathrm{HTN}^{[30,31]}$. The content of the leaflet includes information on diabetes/ HTN such as definition, risk factors, normal values of blood sugar level/blood pressure, complications, dietary requirements, exercise, lifestyle modifications and controlling blood sugar levels/blood pressure to overcome further complications and the information of commonly prescribed medications. The content of the PIL was validated by an expert committee consisting of a physician and four academic pharmacists. The changes were affected as per the directions of the expert committee and the leaflet has been prepared accordingly. Prepared PILs were assessed for Flesch Reading Ease (FRE) and Flesch-Kincaid Grade Level (FK-GL) scores by using MS Office 2007. Readability of the leaflets as per FRE and FK-GL depends on the 
use of polysyllables, sentence length. Taking these issues into consideration, certain modifications were made in the leaflet in order to improve the scores of the leaflet. The score between 60 and 70 is largely considered acceptable. The following scale is used to assess the ease of readability in a document. Very easy (90-100), easy (80-89), fairly easy (70-79), standard (60-69), fairly difficult (50-59), difficult (30-49) and very confusing $(0-29)^{[32]}$.

The prepared, validated and best scored English leaflets were assessed for the characteristics of layout and design of PIL by using Baker Able Leaflet Design (BALD $)^{[33]}$. Modifications like font, alignment, use of pictures and use of good quality paper have been carried out. After preparing the English leaflets with a good readability, layout, and design, PILs were then translated into Kannada and Malayalam with the help of experts who are familiar with the language and also medical terminology. Translated leaflets were then subjected to further validation tests. To check the consistency of translated materials, translated leaflet were back-translated into English from Kannada and Malayalam by language experts. The back-translated and original versions of leaflets were reviewed by a set of experts to find out the difference between the versions. After the validation, it was found that both the original and back-translated versions do not differ significantly. After the validation of translated leaflets, the leaflets were assessed for characteristics of layout and design by using BALD ${ }^{[33]}$.

\section{Readability testing of PILs on the patients:}

Readability testing of PILs on diabetes and HTN was performed on diabetic and hypertensive patients, who visited outpatient medical department of the hospital during the study period. Patients with minimum primary educational background have been selected from the three outpatient medicine units. The inclusion criterion was based on the patients who were diagnosed with diabetes and HTN more than $18 \mathrm{y}$ of age with a written informed consent. The demographic details such as age, gender, and educational status, the length of disease, prescribed medications, and social habits of the all the included patients were documented in patient profile form.

\section{Sample size:}

The sample size was calculated on the basis of the change in patient's knowledge of user-testing scores from baseline (pre-intervention) to post-intervention scores by using the following formula mentioned in the similar study conducted by Mateti et al. According to the equation, the minimum sample required for each disease in this study is $40^{[34]}$. The patients were selected by convenience sampling. $n=\left(Z_{1-\alpha / 2}+Z_{1-\beta}\right)^{2} \sigma^{2}$ $\mathrm{d}^{2}+2 ; \sigma=10, Z_{1-\alpha / 2}$ is 1.96 (for $\alpha=5 \%$ ), where, $Z_{1-\beta}$ is 0.84 for $80 \%$ power; $\sigma$ is the mean of the two standard deviations; $d$ is the minimum significant difference in the two groups.

For the user-testing of PILs, 10 multiple choice questions were prepared based on the content of the leaflet on each disease. The questionnaire was validated by subject experts. A total of 15 patients participated in each of English and Kannada languages and 10 patients in the Malayalam language in each disease PIL. During the user-testing, baseline knowledge has been carried out before providing the PIL followed by provision of the leaflet to the patients. After allowing the patients to read the leaflet for a period of $20 \mathrm{~min}$, patients have again administered with a set of questions to assess their knowledge. At the end of the user-testing, these scores were documented in a separate worksheet along with demography of the patient. After knowledge assessment, patients have then asked to document their opinion about the layout and design in a rating form. Patients have provided with designed leaflet for their assessment on leaflets. At the end of the study, the responses were evaluated using the following formula ${ }^{[34]}$, response evaluation $=$ (total number of correct responses of patient/total number of actual responses) $\times 100$.

After assessing the knowledge about the information leaflets, the opinion of the patients was elicited about the content, layout, and design in a rating form containing 5 questions with a score range on a 4-1 scale. The maximum possible score for the user opinion is 20 . The interpretation of the scores is as follows; if the score of legibility and content of the PILs is ' $20-14$ ' considered as good, '14-9' considered as average, $<9$ considered as poor PIL ${ }^{[34]}$. User-testing and user opinion testing questionnaire was validated before assessing the knowledge and user-opinion from the patients by an expert committee.

\section{Statistical analysis:}

Descriptive statistics was used to summarize the data and the user-testing data of baseline and after $20 \mathrm{~min}$, scores were calculated by using paired student t-test with a p-value less than 0.05 considered as statistically significant. Data were analysed using SPSS version 15 software. 


\section{RESULTS AND DISCUSSION}

PILs on diabetes, HTN and related medications were prepared in English version according to the guidelines. The prepared PILs were validated with the expert committee. After validation, the PILs were assessed for readability by FRE and FK-GL scores, and layout and design using BALD. The PILs were then translated into Kannada and Malayalam languages with the help of language experts. The translated PIL is validated with the experts and modifications have affected according to their suggestions. The final version of diabetes and HTN PILs in English, Kannada and Malayalam languages was assessed for user-testing in patients with diabetes and HTN.

After the preparation of English version of diabetes and HTN PIL, the PIL readability was assessed by using FRE and FK-GL scores. After the assessment of readability scores, to improve the scores, the leaflets were modified and readability scores were assessed, which have recorded improvement after each modification. The final FRE score achieved was 70.4 and FK-GL score achieved was 6.3 for diabetes PIL and both the scores, rates the diabetes leaflet as 'fairly easy'. The final FRE score achieved for HTN PIL was 68.3 and FK-GL score achieved was 6.9 and both the scores rate the HTN leaflet as 'standard'. The results in detail are presented in Table 1 . The mean BALD assessment score for the english version of both diabetes and HTN leaflets was 30 and for Kannada and Malayalam version was 28 each. Evaluation of the BALD assessment scores for diabetes PIL is shown in Table 2. Similarly, we calculated a BALD score for all the version of diabetes and HTN PIL.

Off the 40 diabetic patients, most of the patients were men $(61.9 \%)$ and $50 \%$ of the patients were educated

\begin{tabular}{|c|c|c|c|}
\hline Condition & $\begin{array}{c}\text { Stage of } \\
\text { preparation of } \\
\text { leaflet }\end{array}$ & FRE score & FK-GL score \\
\hline \multirow{3}{*}{ Diabetes } & 1 & 65.2 & 7.2 \\
\hline & 2 & 66.7 & 7 \\
\hline & 3 & 70.4 & 6.3 \\
\hline \multirow{3}{*}{ Hypertension } & 1 & 60.5 & 7.9 \\
\hline & 2 & 65.2 & 7.2 \\
\hline & 3 & 68.3 & 6.9 \\
\hline
\end{tabular}

FRE=Flesch Reading Ease, FK-GL=Flesch Kincaid Grade Level
TABLE 2: BALD ASSESSMENT SCORE FOR DIABETES PIL IN ENGLISH LANGUAGE

\begin{tabular}{|c|c|c|c|c|}
\hline $\begin{array}{l}\text { Design } \\
\text { characteristics }\end{array}$ & 3 points & 2 points & 1 point & 0 point \\
\hline $\begin{array}{l}\text { Lines } 50-89 \\
\text { mm long }\end{array}$ & & & Yes & No \\
\hline $\begin{array}{l}\text { Separation } \\
\text { between lines }\end{array}$ & $>2.8 \mathrm{~mm}$ & $\begin{array}{c}2.2-2.8 \\
\mathrm{~mm}\end{array}$ & & $<2.2 \mathrm{~mm}$ \\
\hline $\begin{array}{l}\text { Lines } \\
\text { unjustified }\end{array}$ & & & Yes & No \\
\hline Serif typeface & & Yes & & No \\
\hline Type size & 12 point & $\begin{array}{l}10-11 \\
\text { point }\end{array}$ & 9 point & $<9$ point \\
\hline $\begin{array}{l}\text { The first line } \\
\text { intended }\end{array}$ & & & Yes & No \\
\hline $\begin{array}{l}\text { Titles lower } \\
\text { case }\end{array}$ & & & Yes & No \\
\hline Italics & & 0 words & $\begin{array}{c}1-3 \\
\text { words }\end{array}$ & $\geq 4$ words \\
\hline Positive advice & & Positive & & Negative \\
\hline $\begin{array}{l}\text { Headings } \\
\text { standout }\end{array}$ & & Yes & & No \\
\hline $\begin{array}{l}\text { Numbers all } \\
\text { Arabic }\end{array}$ & & & Yes & No \\
\hline Boxed text & & & $0-1$ box & $>1$ box \\
\hline Pictures & $\begin{array}{l}\text { Words } \\
\text { could not } \\
\text { replace }\end{array}$ & $\begin{array}{l}\ln \\
\text { between }\end{array}$ & $\begin{array}{l}\ln \\
\text { between }\end{array}$ & $\begin{array}{c}\text { None of } \\
\text { superfluous }\end{array}$ \\
\hline $\begin{array}{l}\text { Number of } \\
\text { colors }\end{array}$ & 4 & 3 & 2 & 1 \\
\hline White space & $>40 \%$ & $30-39 \%$ & $20-29 \%$ & $<20 \%$ \\
\hline Paper quality & $>90$ gsm & $\begin{array}{l}75-90 \\
\text { gsm }\end{array}$ & & $<75$ gsm \\
\hline
\end{tabular}

$\mathrm{Mm}$ is millimeter and gsm is the paper thickness in grams per square meter

till high school. Out of 40 hypertensive patients most of the patients were men $(59.5 \%)$ and the majority of the patients are educated till high school (52.5\%). The other demographic details of the diabetic and hypertensive patients such as age, BMI, social habits such as smoking and taking alcohol were summarized in Table 3.

User-testing of PILs in different languages has been carried out in patients. As per the sample size, a total of 40 each of diabetes and hypertensive patients were included in the study. Among them, 15 patients each participated in English and Kannada version and 10 patients in Malayalam version in user-testing of PIL of each disease, respectively. User testing is done by administering validated knowledge based questionnaire on diabetes and HTN, before and after providing respective PILs to the patients. It was shown that the significant improvement in knowledge-based post-test scores when compared to pretest scores in diabetes 
and hypertensive patients of all the three languages. Detailed results are represented in Table 4.

After assessing the knowledge, the overall user opinion of legibility and content of diabetes and HTN PILs has been evaluated using same patients. The majority of the patients have rated the diabetes leaflets as good (57.5\%) followed by average (40\%) and the HTN leaflets have been rated good $(67.5 \%)$ and followed by average $(32.5 \%)$. The detailed user-opinion scores of English, Kannada and Malayalam versions of diabetes and HTN PILs are summarized in Table 5.

TABLE 3: DEMOGRAPHIC DETAILS OF DIABETES AND HYPERTENSIVE PATIENTS

\begin{tabular}{|c|c|c|}
\hline Demographic details & $\begin{array}{c}\text { Diabetic } \\
\text { patients, } \\
(n=40)\end{array}$ & $\begin{array}{c}\text { Hypertensive } \\
\text { patients } \\
(n=40)\end{array}$ \\
\hline Age in years $($ mean $\pm S D)$ & $58.26 \pm 11$ & $60 \pm 7.46$ \\
\hline $\begin{array}{l}\text { Gender } \\
\text { Male } \\
\text { Female }\end{array}$ & $\begin{array}{l}26(61.9) \\
14(33.3)\end{array}$ & $\begin{array}{l}25(59.5) \\
15(35.7)\end{array}$ \\
\hline $\begin{array}{l}\text { Educational status } \\
\text { Primary school } \\
\text { Middle school } \\
\text { High School } \\
\text { Intermediate } \\
\text { Graduate }\end{array}$ & $\begin{array}{c}- \\
1(2.5) \\
20(50) \\
7(17.5) \\
12(30)\end{array}$ & $\begin{array}{c}- \\
3(7.5) \\
21(52.5) \\
7(17.5) \\
9(22.5)\end{array}$ \\
\hline $\begin{array}{l}\text { BMI }\left(\mathrm{kg} / \mathrm{m}^{2}\right) \\
\text { Underweight }(<18.50) \\
\text { Normal range }(18.50- \\
24.99) \\
\text { Overweight }(25.00-29.99) \\
\text { Obese }(\geq 30.00)\end{array}$ & $\begin{array}{c}- \\
25(62.5) \\
12(30) \\
2(5)\end{array}$ & $\begin{array}{c}- \\
24(60) \\
12(30) \\
4(10)\end{array}$ \\
\hline $\begin{array}{l}\text { Smoking } \\
\text { Yes } \\
\text { No }\end{array}$ & $\begin{array}{c}4(10) \\
36(90)\end{array}$ & $\begin{array}{c}3(7.5) \\
37(92.5)\end{array}$ \\
\hline $\begin{array}{l}\text { Alcohol } \\
\text { Yes } \\
\text { No }\end{array}$ & $\begin{array}{c}5(12.5) \\
35(87.5)\end{array}$ & $\begin{array}{l}10(25) \\
30(75)\end{array}$ \\
\hline
\end{tabular}

PILs can act as educational material for providing patient education regarding disease, medications and lifestyle modifications for better patient outcomes. It is well established that patient education and patient involvement can lead to a better control over disease ${ }^{[35]}$. A diabetic patient should have a working knowledge of diabetes such as symptoms, diabetic care and management for reducing the risk of hospitalization due to complications and for a better patient compliance ${ }^{[36,37]}$. HTN is a common condition, the occurrence of which is set to increase in the aging population, sedentary lifestyle and obesity ${ }^{[10]}$. Studies have shown that dietary habits are an important lifestyle factor impacting the risk of developing $\mathrm{HTN}^{[10]}$. The present study was planned with an initiative to develop PILs on diabetes and HTN in south Indian languages like Kannada and Malayalam and to validate the leaflet for readability and user-testing. Among healthcare professionals, physicians and pharmacists play a significant role in the diagnosis of the disease and its management. Hence their opinion is of paramount importance. In the present study, the content of PILs has been validated by a physician and four academic pharmacists. Similarly, in studies conducted by Adepu and Swamy the content in the information leaflets has been validated by physicians and pharmacists ${ }^{[38]}$. As per a study conducted by Mateti et al. the content validation has been done by three physicians and two academic pharmacists ${ }^{[34]}$. In the study conducted by Roy et al. and the content validity has been done only by physicians ${ }^{[39]}$. In the present study, user-testing was used to assess the readability of the leaflets. Usertesting is the accurate method to assess the readability of the leaflets in any language.

The readability assessed by formulas FRE and FK-GL can only be applied to the English version leaflets and

TABLE 4: USER-TESTING OF DIABETES AND HYPERTENSION PILS IN THREE DIFFERENT LANGUAGE VERSIONS

\begin{tabular}{lccc}
\hline $\begin{array}{l}\text { Type of users/ } \\
\text { languages }(\text { number of patients) }\end{array}$ & Pretest scores $($ mean \pm SD) & Post-test scores (mean \pm SD) & Mean difference $(95 \% \mathrm{Cl})$ \\
\hline DM/English $(\mathrm{n}=15)$ & $43.26 \pm 17.91$ & $92.14 \pm 9.73$ & $48.87(41.09,56.65)^{*}$ \\
HTN/English $(\mathrm{n}=15)$ & $63.28 \pm 16.68$ & $91.56 \pm 11.64$ & $28.28(19.19,37.37)^{*}$ \\
DM/Kannada $(\mathrm{n}=15)$ & $47.59 \pm 22.31$ & $87.28 \pm 13.09$ & $39.68(28.47,50.89)^{*}$ \\
HTN/Kannada $(\mathrm{n}=15)$ & $64.30 \pm 19.49$ & $90.70 \pm 11.28$ & $26.40(18.94,33.86)^{*}$ \\
DM/Malayalam $(\mathrm{n}=10)$ & $42.91 \pm 21.67$ & $82.85 \pm 16.01$ & $39.94(31.49,47.87)^{*}$ \\
DM/Malayalam $(\mathrm{n}=10)$ & $61.39 \pm 6.90$ & $87.13 \pm 10.55$ & $25.74(16.59,34.89)^{*}$ \\
Overall DM PIL users $(\mathrm{n}=40)$ & $44.80 \pm 20.17$ & $87.99 \pm 12.97$ & $43.19(37.65,48.73)^{*}$ \\
Overall HTN PIL users $(\mathrm{n}=40)$ & $63.19 \pm 15.77$ & $90.13 \pm 11.10$ & $26.94(22.08,31.80)^{*}$ \\
\hline
\end{tabular}

$\mathrm{DM}=$ diabetic patients, $\mathrm{HTN}=$ hypertensive patients, $\mathrm{SD}=$ standard deviation, $\mathrm{Cl}=$ confidence interval. $\mathrm{p} \leq 0.0001$ statistically significant compared to pre-test 
TABLE 5: USER-OPINION SCORES OF DIABETES AND HYPERTENSION PILS OF THREE DIFFERENT LANGUAGES

\begin{tabular}{|c|c|c|c|}
\hline $\begin{array}{l}\text { Languages } \\
\text { (no. of } \\
\text { patients) }\end{array}$ & $\begin{array}{l}\text { Interpretation } \\
\text { of scores }\end{array}$ & $\begin{array}{c}\text { No. of } \\
\text { diabetic } \\
\text { patients, (\%) }\end{array}$ & $\begin{array}{c}\text { No. of } \\
\text { hypertensive } \\
\text { patients, (\%) }\end{array}$ \\
\hline \multirow{3}{*}{$\begin{array}{l}\text { English } \\
(n=15)\end{array}$} & Good & $7(17.5)$ & $10(25)$ \\
\hline & Average & 7 (17.5) & $5(12.5)$ \\
\hline & Poor & $1(2.5)$ & \\
\hline \multirow{3}{*}{$\begin{array}{l}\text { Kannada } \\
(\mathrm{n}=15)\end{array}$} & Good & $10(25)$ & $9(22.5)$ \\
\hline & Average & $5(12.5)$ & $6(15.0)$ \\
\hline & Poor & & \\
\hline \multirow{3}{*}{$\begin{array}{l}\text { Malayalam } \\
(\mathrm{n}=10)\end{array}$} & Good & $6(15.0)$ & $8(20.0)$ \\
\hline & Average & $4(10.0)$ & $2(5.0)$ \\
\hline & Poor & - & - \\
\hline \multirow{3}{*}{$\begin{array}{l}\text { Overall } \\
\text { diabetes PIL } \\
\text { users } \\
(\mathrm{n}=40)\end{array}$} & Good & $23(57.5)$ & 27 (67.5) \\
\hline & Average & $16(40)$ & $13(32.5)$ \\
\hline & Poor & $1(2.5)$ & - \\
\hline
\end{tabular}

readability of other language leaflets is not possible by this method. In the present study, the readability of English version of leaflets was assessed by FRE and FK-GL and English version of leaflets along with other languages (Kannada and Malayalam), readability was assessed by user-testing. The best readability scores achieved for the diabetes are FRE 70.4 and FK-GL 6.3, while for HTN PILs, FRE 68.3 and FK-GL 6.9. The similar study conducted by Adepu and Swamy ${ }^{[38]}$ has shown the best readability scores have been achieved for diabetes (FRE 84) and HTN (FRE 82) PILs. Whereas the study conducted by Roy et al. has shown the best FRE readability scores achieved for the diabetic foot ulcer PILs are $69.9^{[38,39]}$. In the present study, these readability scores suggest that prepared diabetes and HTN PILs are 'fairly easy' and standard, respectively. Easiness in readability in PIL can be improved by using simple English words. It has been documented that a well-designed leaflet can contribute to responsible medicine-taking by patients and improves patients' ability to find and understand the information provided ${ }^{[40]}$. The mean BALD assessment score of English, Kannada and Malayalam leaflets was better than that of the leaflets prepared by the similar studies $^{[34,38,39,41]}$. One of the drug companies prepared 30 customer PILs in Australia and subjected them for readability and design characteristics. Results of this study showed that mean FRE score of all the PILs was 51 and mean BALD criteria score was 17, suggesting poor readability and design characteristics. It was also shown that a leaflet with good readability scores and design characters like pictograms, font sizes, space between sentences and paper quality will improve the patient's comprehension and acceptability ${ }^{[40]}$. In the present study, the inclusion of pictograms in PILs has helped the patients recalling capacity (such as causes of the disease, symptoms, diet and lifestyle modification). The same has been reflected in the results of user testing using a knowledge based questionnaire for diabetes and HTN. Patients enrolled in the study are with various educational backgrounds and with a history of various lengths of disease duration. Many patients are from school and pre-university educational levels. In a study reported by Bernardini et al., the majority of respondents considered that the use of symbols and pictograms has been helpful in finding the required information ${ }^{[43]}$. It would be interesting to establish if symbols or picture sequences can have a role in increasing the clarity and understanding of a specific message ${ }^{[42]}$. The pictograms and symbols may significantly enhance readability and comprehension of the PILs. It is evident from this study that the post-interventional PILs knowledgebased user-testing scores have significantly improved mean baseline scores from 44.80 to 87.99 in diabetic patients and 63.19 to 90.13 in hypertensive patients. The pre- and post-interventional PIL study conducted in the community pharmacy has shown that the recall drug information has significantly improved from 30 to $65 \%{ }^{[43]}$. The verbal advice along with PIL is shown to have improved knowledge levels in recognizing the uses and side effects of medications from 40 to $67 \%{ }^{[44]}$. Similar studies conducted by others with PILs as an educational intervention have a significant impact on the KAP among the patients with diabetes, HTN, asthma peptic ulcer and rheumatoid arthritis ${ }^{[38,45-47]}$. The impact of pictograms in PILs in recalling the information have shown similar improvement ${ }^{[32,48]}$. Most of the published studies have not assessed the user-testing and user-opinion on the leaflets, which the present study attempts as they are one of the important stakeholders in patient education. The results of this study reveal that $57.5 \%$ of diabetic and $67.5 \%$ of hypertensive patients rated the leaflets content, legibility and design as good. The objective of the present study is to prepare good quality PILs and to follow the user-testing method as per European guidelines on the Indian population.

The information leaflets in the present study are in accordance with the standard readability and good layout and design criteria scores and in tune with the patients' education and comprehension. FRE and FK-GL scores rate have shown that the leaflet was 'fairly easily' readable. BALD scores have been evaluated for all the prepared leaflets and have shown that all of them have a good score. User-testing of 
leaflets has imparted comprehensible awareness regarding the expectations and understanding of the end users and prepared leaflets have subjected to usertesting irrespective of the language. Leaflets with good layout and design have easily acknowledged by the end users. The present study has recorded a significant improvement in the knowledge levels after reading the validated leaflets. More than $60 \%$ of the patients have rated the leaflets content, readability and design as good. It has also been observed that the patient education with information leaflets by the clinical pharmacist has shown significant improvement in the knowledge of diabetes and hypertensive patients towards their disease management, which showing the effectiveness of a PIL.

\section{Conflicts of interest:}

There are no conflicts of interest.

\section{Financial support and sponsorship:}

Nil.

\section{REFERENCES}

1. Gupta U, Sharma S, Sheth PD. Improving medicine usage through patient information leaflets in India. Trop Doct 2005;35:164-6.

2. Al-Maskari F, El-Sadig M, Al-Kaabi JM, Afandi B, Nagelkerke N, Yeatts KB. Knowledge, attitude, and practices of diabetic patients in the United Arab Emirates. PLoS One 2013;8(1):e52857.

3. https://ec.europa.eu/health/sites/health/files/files/eudralex/ vol-1/dir_2001_83_cons2009/2001_83_cons2009_en.pdf.

4. http://ec.europa.eu/health/sites/health/files/files/eudralex/vol2/c/2009_01_12_readability_guideline_final_en.pdf.

5. Dowse R, Ehlers M. Medicine labels incorporating pictograms: do they influence understanding and adherence? Patient Edu Couns 2005;58:63-70.

6. Bayrak G, Colak R. Patient education in treatment of diabetes. J Exp Clin Med 2012;29:7-11.

7. Kheir N, Greer W, Yousif A, Al Geed H, Al Okkah R. Knowledge, attitude and practices of Qatari patients with type 2 diabetes mellitus. Int J Pharm Pract 2011;19:185-91.

8. Norris SL, Lau J, Smith SJ, Schmid CH, Engelgau MM. Selfmanagement education for adults with type 2 diabetes: A meta-analysis of the effect on glycemic control. Diabetes Care 2002;25:1159-71.

9. McMurray SD, Johnson G, Davis S, McDougall K. Diabetes education and care management significantly improve patient outcomes in the dialysis unit. Am J Kidney Dis 2002;40:566-75.

10. Buttar HS, Li T, Ravi N. Prevention of cardiovascular diseases: Role of exercise, dietary interventions, obesity and smoking cessation. Exp Clin Cardiol 2005;10:229-49.

11. Arul KS, Julie KY, Jiji J, Palanisamy S. Development and implementation of a patient information leaflet on hypertension and to assess its effectiveness. Int $\mathrm{J}$ Pharm Tech Res 2009;1:713-19.

12. Appel LJ, Moore TJ, Obarzanek E, Vollmer WM, Svetkey LP, Sacks FM, et al. A clinical trial of the effects of dietary patterns on blood pressure. DASH Collaborative Research Group. N Engl J Med 1997;336:1117-24.

13. DiPiro JT, Talbert RL, Yee GC, Matzke GR, Wells BG, Posey LM. Pharmacotherapy: A Pathophysiologic Approach. 7th ed. New York: McGraw-Hill Medical; 2011. p. 139-71.

14. DiPiro JT, Talbert RL, Yee GC, Matzke GR, Wells BG, Posey LM. Pharmacotherapy: A Pathophysiologic Approach. 7th ed. New York: McGraw-Hill Medical; 2011. p. 1205-42.

15. Stephen MS, John R, White Jr, Campbell RK. Diabetes In: Herfindal ET, Gourley DR, editors. Textbook of Therapeutics Drug and Disease management. 7th ed. Philadelphia, Pennsylvania: Lippincott Williams \& Wilkins; 2000. p. 377406.

16. Weibert RT. Hypertension In: Herfindal ET, Gourley DR, ed. Textbook of Therapeutics Drug and Disease management. 7th ed. Philadelphia, Pennsylvania: Lippincott Williams \& Wilkins; 2000. p. 795-824.

17. Longo DL, Fauci AS, Kasper DL, Hauser SL, Jameson J, Loscalzo J. Harrison's Principles of Internal Medicine. 18th ed. New York: McGraw Hill Education; 2012. p. 693-700.

18. Longo DL, Fauci AS, Kasper DL, Hauser SL, Jameson J, Loscalzo J. Harrison's Principles of Internal Medicine. 18th ed. New York: McGraw Hill Education; 2012. p. 942-48.

19. http://www.micromedexsolutions.com/(cited: Oct $\left./ 6^{\text {th }} / 2014\right)$.

20. https://www.uptodate.com/contents/diabetes-mellitus-type-2overview-beyond-the-basics.

21. https://www.uptodate.com/contents/overview-ofhypertension-in-adults.

22. http://emedicine.medscape.com/article/117853-overview.

23. http://emedicine.medscape.com/article/241381-overview.

24. https://medlineplus.gov/diabetestype $2 . h t m l$.

25. https://medlineplus.gov/highbloodpressure.html.

26. http://www.webmd.com/hypertension-high-blood-pressure/ guide/hypertension-treatment-overview\#1.

27. http://www.webmd.com/diabetes/guide/glycatedhemoglobin-test-hba1c.

28. American Diabetes Association. Standards of medical care in diabetes-2013. Diabetes Care 2013;36:S11-66.

29. Canadian Diabetes Association Clinical Practice Guidelines Expert Committee, Goldenberg R, Punthakee Z. Clinical practice guidelines: definition, classification and diagnosis of diabetes, prediabetes and metabolic syndrome. Can J Diabetes 2013;37:S8-S11.

30. James PA, Oparil S, Carter BL, Cushman WC, DennisonHimmelfarb C, Handler J, et al. Evidence-based guideline for the management of high blood pressure in adults: report from the panel members appointed to the Eighth Joint National Committee (JNC 8). JAMA 2014;311:507-20.

31. Nguyen H, Odelola O, Rangaswami J, Amanullah A. A review of nutritional factors in hypertension management. Int $\mathrm{J}$ Hypertens 2013;1144-50.

32. Basara LR, Juergens JP. Patient package inserts readability and design. Am Pharm 1994;34:48-53.

33. Baker S. Who can read Consumer Product Information? Aust J Hosp Pharm 1997;27:126-31.

34. Mateti UV, Nagappa AN, Attur RP, Bairy M, Nagaraju SP, 
Mallayasamy S, et al. Preparation, validation, and usertesting of pictogram-based patient information leaflets for hemodialysis patients. Saudi Pharm J 2015;23:621-5.

35. Al Bimani ZS, Khan SA, David P. Evaluation of T2DM related knowledge and practices of Omani patients. Saudi Pharm J 2015;23:22-7.

36. Lockington TJ, Farrant S, Meadows KA, Dowlatshahi D, Wise PH. Knowledge profile and control in diabetic patients. Diabet Med 1988;5:381-6.

37. Majra JP, Acharya D. Awareness regarding self-care among diabetics in rural India. Middle East J Fam Med 2009;7:12.

38. Adepu R, Swamy MK. Development and evaluation of patient information leaflets (PIL) usefulness. Indian J Pharm Sci 2012;74:174-8.

39. Roy RT, Sekhar MS, Rodrigues GS, Rajesh V. Preparation and readability assessment of patient information leaflets for diabetic foot ulcers. J Soc Health Diabetes 2013;1:79-81.

40. Dickinson D, Raynor DK, Duman M. Patient information leaflets for medicines: using consumer testing to determine the most effective design. Patient Edu Couns 2001;43:147-59.

41. Rajan MS, Mathew J, Suhaj A, Rajesh V, Manu MK. Study to assess the utility of cloze test in readability assessment of patient information leaflets in English and Indian languages. Asian J Pharm Health Sci 2013;3:824-9.

42. Hill J, Bird H. The development and evaluation of a drug information leaflet for patients with rheumatoid arthritis. Rheumatology (Oxford) 2003;42:66-70.

43. Bernardini C, Ambrogi V, Perioli LC, Tiralti MC, Fardella G. Comprehensibility of the package leaflets of all medicinal products for human use: a questionnaire survey about the use of symbols and pictograms. Pharmacol Res 2000;41:679-88.

44. Morris LA, Halperin JA. Effects of written drug information on patient knowledge and compliance: a literature review. Am J Public Health 1979;69:47-52.

45. Carina RL, Anthony LG, Sandra W. Developing community pharmacy services wanted by local people: Information about advice about prescription medicines. Int J Pharm Pract 1996;4:94-102.

46. Sathvik BS, Mangasuli S, Narahari MG, Gurudev KC, Parthasarathi G. Medication knowledge of hemodialysis patients and the influence of clinical pharmacist- provided education on their knowledge. Indian J Pharm Sci 2007;69:232-9.

47. Gibbs S, Waters WE, George CF. Benefits of prescription information leaflets. Part 1. Br J Clin Pharmacol 1989;27:723-39.

48. Mansoor LE, Dowse R. Effect of pictograms on readability of patient information materials. Ann Pharmacother 2003;37:1003-9. 